\title{
Escherichia coli Generate Oxidative Stress and Enhance Lipid Peroxidation in the Kidney of the Rat
}

\section{Amiy Dutt Chaturvedi ${ }^{1}$, Nagarajan K ${ }^{2}$, Dharm Pal ${ }^{3}$ and Awanish Kumar ${ }^{4 *}$}

${ }^{1}$ Department of Plant Ecology and Environmental Science, CSIR-National Botanical Research Institute, Lucknow, India

${ }^{2}$ Department of Veterinary Pathology, Madras Veterinary College, Chennai, India

${ }^{3}$ Department of Chemical Engineering, National Institute of Technology Raipur, India

${ }^{4}$ Department of Biotechnology, National Institute of Technology Raipur, India

\begin{abstract}
The urinary tract is generally infected by Escherichia coli bacteria. They commonly originate in the patient's own bowel, and infection occurs mostly via the ascending route. In this study, we have observed the influence of $E$. coli on oxidative stress generation and lipid peroxidation in the kidney of the rat. E. coli were taken from the soil, urine, buffalo intestine and goat intestine for this study. Rats were infected with isolated $E$. coli from different sources and Lipid peroxidation, glutathione assay was done to achieve the goal of this study. Percentage survival data showed that the $E$. coli isolated from urine had more lethargy phenomena because their survival present was $66.66 \%$ and the mortality rate was higher in this group. Although $E$. coli isolated from Goat intestine has also shown the same mortality, but the $E$. coli isolated from urine sample shown this mortality from the second day whereas the $E$. coli isolated from goat intestine from the third day. By and large data indicated that the $E$. coli isolated from urine sample generated high oxidative stress and damage rat kidney because the kidney is an organ frequently exposed to oxidative stress. Overall, free radical generated due to $E$. coli infection further enhances lipid peroxidation in the rat which is harmful to the physiology because it may cause a renal disorder in the rat.
\end{abstract}

Keywords: E. coli; Virulence; Rat; Kidney; Lipid peroxidation

\section{Introduction}

Our gastro-intestinal tract is a biologically diverse and complicated system which contains numerous bacterial species. Intestinal microbes harbor a diverse microbial community, often containing opportunistic bacteria with virulence potential [1]. Both the host and bacteria are thought to derive benefit from each other. While most of the activities of the normal flora benefit their host, some of the normal flora are parasitic (live at the expense of their host), and some are pathogenic (capable of producing disease) [2]. Diseases that are produced by the normal flora in their host are called endogenous diseases. Most endogenous bacteria are opportunistic in infection [1]. Among endogenous bacteria, Escherichia coli are generally harmless for humans but some of them are parasitic and may cause life dangerous complication like a severe kidney damage function or even sepsis. E. coli may live for months in water and ground but they get the opportunity they multiply very quickly and cause digestion problems $[3,4]$. We can describe E. coli as opportunistic bacteria only in the specific situation when it arrives from the intestine to other organs and tissues and causes illnesses by producing Shiga toxin $[5,6]$. The most frequent are urinary tract and sexual organs infections. E. coli outbreak has killed many persons in the USA in and other parts of the world $[7,8]$. Virulence factors of E. coli are studied and reported in different population by many research groups [9-13]. E. coli infection was also reported in domestic animals like rabbits, cats, dogs, goats and horses [14]. The main site of $E$. coli infection is kidney and their infection is spread through blood [15]. Therefore in this study kidney and serum burden was measured after total dosages regimen (infection time period) and data of their dilution series showed that kidney and blood burden was higher in buffalo having $E$. coli infection. The sources of $E$. coli were soil, urine, buffalo intestine and goat intestine. This study was designed to investigate the antibiotic resistance, serum analysis and virulence of $E$. coli (isolated from the different source) in the rat.

\section{Materials and Methods}

\section{Concept design of the study}

The present study was emerged from isolation of $E$. coli from soil sample, urine sample, goat $(G)$ and buffalo (B) intestine. They were collected locally and stored at $-20^{\circ} \mathrm{C}$ until use.

\section{Isolation of $\boldsymbol{E}$. coli bacteria}

Samples were firstly inoculated in $1 \%$ tryptone broth for 24 hours for the isolation of $E$. coli from different sources mentioned above. Then the broth was again inoculated on Mac-konkey Agar media for $24 \mathrm{hrs}$. Then the pink colonies were selected and again transferred on EMB agar media for $24 \mathrm{hrs}$. The metallic shine colonies were selected and stored in LB agar media for at $4^{\circ} \mathrm{C}$ until use.

\section{Biochemical tests for identification of bacteria}

Urease test: Urea agar medium and urea broth were prepared and sterilized by autoclaving at $121^{\circ} \mathrm{C}$. Media was poured into the tubes and allows them to solidify in a slanting position to form slopes. The tubes were labeled with the name of the inoculating organism. Inoculate the liquid and agar media with a transfer loop. Incubate the slants/broths for $24-48 \mathrm{hrs}$ at $37^{\circ} \mathrm{C}$

Carbohydrate catabolism by microorganisms test: Glucose

*Corresponding author: Awanish Kumar, Department of Biotechnology, National Institute of Technology, Raipur - 492010, Chhattisgarh, India, Tel: 8871830586 E-mail: drawanishkr@gmail.com, awanik.bt@nitrr.ac.in

Received: October 31, 2016; Accepted: January 21, 2017; Published January 24, 2017

Citation: Chaturvedi AD, Nagarajan K, Pal D, Kumar A (2017) Escherichia coli Generate Oxidative Stress and Enhance Lipid Peroxidation in the Kidney of the Rat. Biochem Anal Biochem 6: 306. doi: 10.4172/2161-1009.1000306

Copyright: $\odot 2016$ Chaturvedi AD, et al. This is an open-access article distributed under the terms of the Creative Commons Attribution License, which permits unrestricted use, distribution, and reproduction in any medium, provided the original author and source are credited. 
Citation: Chaturvedi AD, Nagarajan K, Pal D, Kumar A (2017) Escherichia coli Generate Oxidative Stress and Enhance Lipid Peroxidation in the Kidney of the Rat. Biochem Anal Biochem 6: 306. doi: 10.4172/2161-1009.1000306

Page 2 of 4

\begin{tabular}{|c|c|c|c|}
\hline E. coli from different sources & Gentamycin & Erythromycin & $20 \pm 1.63$ \\
\hline Soil & $20 \pm 1.81$ & $33.5 \pm 2.72$ \\
\hline Urine & $23 \pm 1.90$ & $22 \pm 1.69$ \\
\hline Buffalo intestine & $22.5 \pm 1.68$ & $22.5 \pm 1.92$ \\
\hline Goat intestine & $24 \pm 1.91$ & $21 \pm 1.64$ \\
\hline
\end{tabular}

Table 1: $E$. coli isolated from different source showing the zone of inhibition (in $\mathrm{mm}$ ) against few antibiotics.

\begin{tabular}{|c|c|c|c|c|c|c|}
\hline Source of isolated $E$. coli & Dosing period & Infection of $E$. coli & Total no. of animals & Survived animals & Dead animals & $\%$ Survival \\
\hline Control & 3 days & PBS solution & 6 & 6 & 0 & $100 \%$ \\
\hline Soil & 3 days & $1 \mathrm{ml}$ of $E$. coli broth & 6 & 6 & 0 & $100 \%$ \\
\hline Urine & 3 days & $1 \mathrm{ml}$ of $E$. coli broth & 6 & 4 & 2 & $66.66 \%$ \\
\hline B. Intestine & 3 days & $1 \mathrm{ml}$ of $E$. coli broth & 6 & 6 & 0 & $100 \%$ \\
\hline G. Intestine & 3 days & $1 \mathrm{ml}$ of $E$. coli broth & 6 & 5 & 1 & $88.88 \%$ \\
\hline
\end{tabular}

Table 2: Surveillance of infected rats with $E$. coli isolated from different sources.

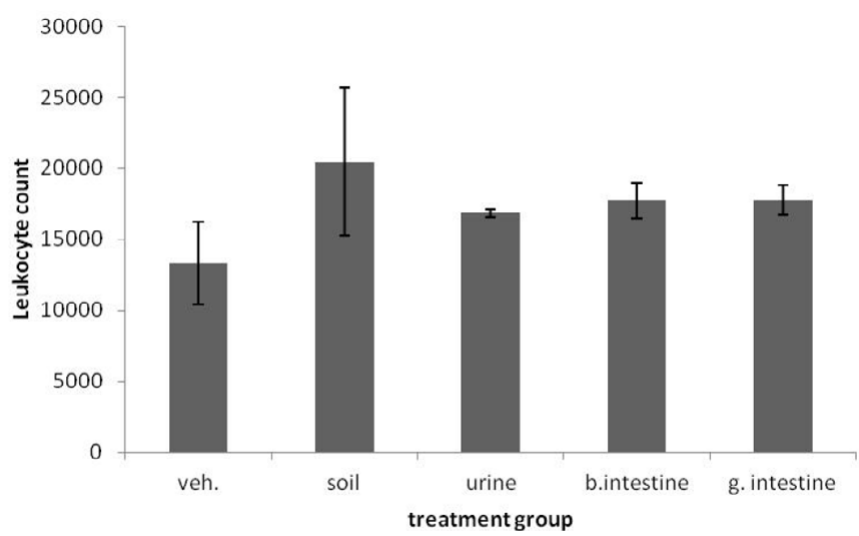

Figure 1: Total leukocyte (WBC) count in experimental rat after infection with $E$. coli isolated from different source mentioned in material and methods section.

media was used to identify the oxidative and fermentative abilities of microorganisms. Acid end products were generated, $\mathrm{pH}$ was lowered and the bromthymol blue indicator was turned yellow.

IMVIC tests: Indole methyl red Voges-Proskauer citrate (IMVIC) test was under taken to identify the $E$. coli in frequent form.

\section{Animals study}

Swiss albino rats of either sex weighing $100 \pm 5$ gm were selected randomly from the animal house of Madras Veterinary College, Chennai, India. They were housed in a controlled room with a $12 \mathrm{~h}$ light dark cycle at the room temperature of $22 \pm 2^{\circ} \mathrm{C}$, humidity $30 \%$ to $60 \%$. They were kept on standard pellet diet (Lipton India Ltd.). Animal maintenance and handling were in accordance to the internationally accepted standard guidelines of Committee for the Purpose of Control and Supervision of Experiment on Animals (CPCSEA). Experiments were conducted according to the guidelines and ethical norms, approved by ministry of social justice and empowerment, government of India. Six rats were taken for each $E$. coli sample isolated from different sources. $10^{9} \mathrm{CFU} / \mathrm{ml}$ broth cultures of $E$. coli strains isolated from different sources were given to experimental animals.

\section{Leucocytes counting}

It was done by using following formula:

$\mathrm{WBC} / \mu \mathrm{L}=\frac{\text { Average of cells } \times \text { Correction for dilution }}{\text { No. of squares counted } \times \text { Volume of one square }}$

\section{Biochemical assays}

Lipid per oxidation (LPO): MDA, an end product of LPO reacts with TBA to form a colored substance. Measurement of MDA by TBA reactivity is the most widely used method for assessing LPO. Lipid peroxidation was measured via the amount of liberated malondialdehye (MDA) in the system that assayed the pink product, as reported earlier [16]. The colored end product was read at $540 \mathrm{~nm}$.

Glutathione (GSH) measurement: Cellular GSH activity was measured according to method of Paglia and Valentine et al. [17]. The rate of change of absorbance during the conversion of NADPH to NADP was recorded using Shimadzu spectrophotometer at $340 \mathrm{~nm}$ for $3 \mathrm{~min}$.

\section{Statistical analysis}

Results were expressed as mean \pm SD (standard deviation). Three sets of experiments were performed and the results were analyzed by One-Way ANOVA (analysis of variance) test. The upper level of significance was chosen as $\mathrm{P}<0.05$ (Significant).

\section{Results}

Pure culture of isolated E. coli from different sources was tested with three antibiotics (Gentamycin, Erythromycin, and Chloramphenicol) to study the inhibition effects. The result is depicted in Table 1. Maximum inhibition was observed by Erythromycine $(33.5 \mathrm{~mm})$ followed by Chloramphenicol $(26.5 \mathrm{~mm})$ for urine isolates cultures. Gentamycine inhibited more to the goat intestine isolate $(24.0 \mathrm{~mm})$. Data surveillance of test animal (Table 2) relieved that out of six animals tests for each group of culture only two were found dead by urine isolate and only one were found dead by goat intestine isolated culture whereas other culture did not cause dead and showed 100\% survival. Variation in 


\begin{tabular}{|c|c|c|c|}
\hline \multirow{2}{*}{ S. No. } & Infection of $\boldsymbol{E}$. coli isolated & \multicolumn{3}{|c|}{ Serum burden (number of $\boldsymbol{E}$. coli \pm SD) } \\
\cline { 3 - 4 } & from different sources & First dilution & Second dilution \\
\hline 1 & Control & $1.00 \pm 0.29$ & $0.00 \pm 0.00$ \\
\hline 2 & Soil & $5.00 \pm 1.31$ & $3.00 \pm 0.96$ \\
\hline 3 & Urine & $2.00 \pm 0.48$ & $1.00 \pm 0.33$ \\
\hline 4 & B. intestine & $693.00 \pm 80.27$ & $420.00 \pm 74.09$ \\
\hline 5 & G. Intestine & $17.00 \pm 5.24$ & $09.00 \pm 3.38$ \\
\hline
\end{tabular}

Table 3: E. coli burden in blood serum of rat.

\begin{tabular}{|c|c|c|c|}
\hline \multirow{2}{*}{ S. No. } & Infection of $E$. coli isolated & \multicolumn{2}{|c|}{ Serum burden (number of $E$. coli \pm SD) } \\
\cline { 3 - 4 } & from different sources & First dilution & Second dilution \\
\hline 1 & Control & $2.00 \pm 0.61$ & $0.00 \pm 0.00$ \\
\hline 2 & Soil & $101.00 \pm 29.64$ & $33.00 \pm 13.19$ \\
\hline 3 & Urine & $213.00 \pm 54.79$ & $122.00 \pm 27.41$ \\
\hline 4 & B. Intestine & $240.00 \pm 61.52$ & $50.00 \pm 17.13$ \\
\hline 5 & G. Intestine & $169.00 \pm 36.74$ & $140.00 \pm 31.18$ \\
\hline
\end{tabular}

Table 4: E. coli burden in kidney of rat.

\begin{tabular}{|c|c|c|}
\hline $\begin{array}{c}\text { S. } \\
\text { No. }\end{array}$ & $\begin{array}{c}\text { Infection of } E \text {. coli isolated from } \\
\text { different sources }\end{array}$ & $\begin{array}{c}\text { LPO level (nM/mg protein } \\
\mathbf{S D})\end{array}$ \\
\hline 1 & Control & $0.54 \pm 0.23$ \\
\hline 2 & Soil & $1.36 \pm 0.83$ \\
\hline 3 & Urine & $4.09 \pm 0.38$ \\
\hline 4 & B. Intestine & $1.69 \pm 0.79$ \\
\hline 5 & G. Intestine & $2.52 \pm 0.30$ \\
\hline
\end{tabular}

Table 5: LPO level in rat infected by $E$. coli isolated from different sources.

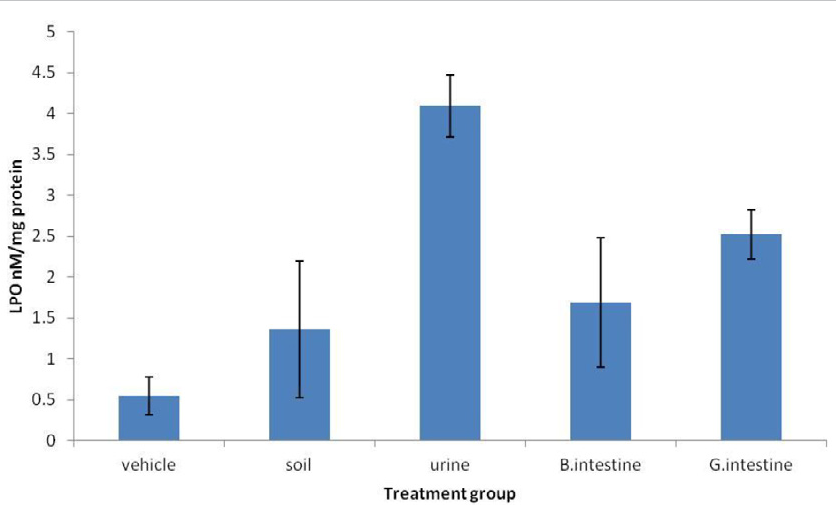

Figure 2: Lipid peroxidation in infected rat showed that there was increase in LPO in treating group and it was found significant from control at $\mathrm{P}<0.05$

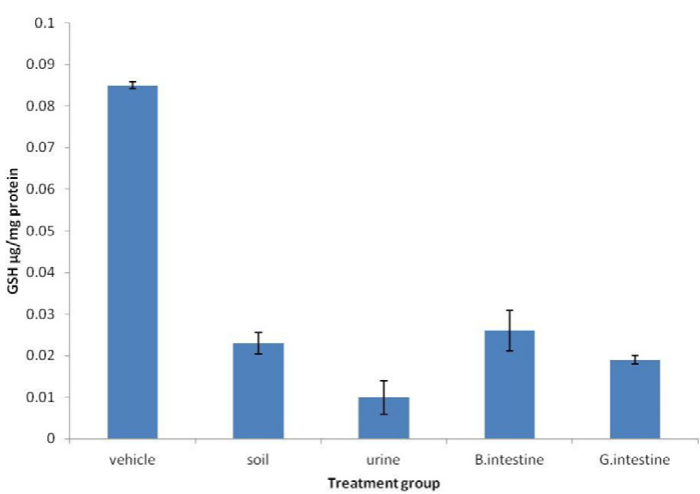

Figure 3: Glutathione measurement showed that there was decrease in GSH level in treated rat and significant from control at $\mathrm{P}<0.05$. white blood cells (WBC) count is one of the important parameters to be assessed when body get infected by any type of microorganism. As immunity of body starts fighting against pathogens, WBC count starts varying. WBC counting of all groups has revealed that infection was higher in E. coli treated group in compare to control group means WBC counting increased phenomena showed infectious phenomena. Here data of WBC counting showed that isolated E. coli had a property to induce disease but these data were not sufficient to differentiate their mortality. Data on WBC count in test animal is depicted in Figure 1.

Kidney and blood burden of $E$. coli isolated from urine was very low but with the respect of lethargy phenomena it is comprehended that $E$. coli isolated from urine was more virulence because their few amount were sufficient to produce disease condition. Presences of $E$. coli in the blood (Table 3 ) has revealed that the maximum E. coli cells were observed in the sample isolated from the buffalo intestine (B) in both dilution followed by samples isolated from the goat intestine (G) and least from soil and urine samples. The burden of E. coli in the kidney due to the E. coli infection was estimated (Table 4). Here minimum E. coli burden was observed from samples isolated from soil and maximum was in buffalo intestine (B).

E. coli is considered as the normal bowel flora of different species of mammals and birds but some strains of $E$. coli possess pathogenic character due to the acquisition of virulent factors. Microbial characteristics associated with virulent $E$. coli include the production of Enterotoxin, Verotoxin, Colicins and Siderophores, type-1 pili and motility, resistance to the lytic action of the host complement and antibiotics. Lipopolysaccharide (LPS) or endotoxins are the principal components of gram-negative bacteria like E. coli. It has been extensively studied as a major factor contributing to the pathogenesis of Gram-negative bacterial infections. Endotoxin is a highly conserved cell wall component that is recognized by the immune system of higher vertebrates as a pathogen-associated molecular pattern (PAMP) and can elicit a systemic inflammatory response. The LPO and GSH estimation (Table 5) (Figures 2 and 3 ) were found significantly different from control at $\mathrm{P}<0.05$. Here maximum $\mathrm{LPO}$ was determined as 4.09 due to treatment with urine samples whereas maximum GSH level was found due to treatment with buffalo intestine samples among the other treatments. With the above-mentioned result, the kidney and serum burden was measured with regimens showed more virulence to cause infection. The increase in LPO and decrease in GSH in treating group cause increase oxidative stress in the kidney that may causes the renal disorder and physiological misbalance.

\section{Discussion}

Due to reactive oxygen species, lipid peroxidation occurred and free radical of PUFA (ploy unsaturated fatty acid) generated and cell damage is continuing by the effect of the ROS. One approach to combat the bacterial induced oxidative stress is the use of antioxidant treatments through intraperitoneal, intravenous, or dietary administration. In this study, LPO level was increased in all treated group of rat and among them LPO level was higher in the group which was infected with E. coli isolated from the urine sample and decreased GSH content. Further the study indicated the increased oxidative stress in treated group and this type of oxidative stress was higher in that group which was infected with $E$. coli isolated from the urine sample. Serum examination was done after infection of $E$. coli isolated from the different sample of soil, urine, buffalo intestine and goat intestine and bacterial burden was high as compared to control (Tables 4 and 5). In all the groups, over one-fourth of the kidneys were infected. Bacteria persisted in high numbers in the infected kidneys. The pathological change observed 
Citation: Chaturvedi AD, Nagarajan K, Pal D, Kumar A (2017) Escherichia coli Generate Oxidative Stress and Enhance Lipid Peroxidation in the Kidney of the Rat. Biochem Anal Biochem 6: 306. doi: 10.4172/2161-1009.1000306

Page 4 of 4

in the infected kidneys may be due to the infiltration of the pelvic epithelium and sub epithelial connective tissue by mononuclear cells and polymorphonuclear leukocytes. With the above mentioned data (result section), the kidney and serum burden of E. coli was measured with regimens showed more virulence to cause infection the antibiotic effect on E. coli are also measured. The increase of LPO and decrease in GSH in treating group may cause increase oxidative stress in the kidney (Figures 2 and 3).

\section{Conclusion}

This study showed the effect of E. coli infection in terms of perturbation of LPO and GSH in experimental animal. Peroxidation of lipids disturbs theintegrity of cell membranes and leads to rearrangement of membrane structure. They produce adverse modifications to cell components, such as lipids, proteins, carbohydrates, DNA and alter physiological functions.

\section{Acknowledgements}

Authors are thankful to Madras Veterinary College, Chennai India and NIT, Raipur, India for providing facility and resources for this work. This research received no specific grant from any funding agency in the public, commercial, or not-for-profit sectors.

\section{References}

1. Pham TA, Clare S, Goulding D, Arasteh JM, Stares MD, et al. (2014) Epithelial IL-22RA1-mediated fucosylation promotes intestinal colonization resistance to an opportunistic pathogen. Cell Host Microbe 16: 504-516.

2. Brett KN, Ramachandran V, Hornitzky MA, Bettelheim KA, Walker MJ, et al. (2003) Stx1c Is the most common Shiga toxin 1 subtype among Shiga-toxin producing Escherichia coli isolates from sheep but not among isolates from cattle. J Clin Microbiol 41: 926-936.

3. Paton AW, Srimanote P, Talbot UM, Wang H, Paton JC (2004) A new family of potent AB5 cytotoxins produced by Shiga toxigenic Escherichia coli. J Exp Med 200: 35-46.

4. Beutin L, Zimmermann S, Gleier K (1998) Human infections with Shiga toxin- producing Escherichia coli other than sero-group. Emeg Infec Dis 4: 635-639.

5. Beutin L, Geiger D, Steinruck H, Zimmermann S, Scheutz F (1993) Prevalence and some properties of verotoxin Shiga-like toxin producing Escherichia coli in seven different species of healthy domestic animals. J Clin Microbiol 31:24832488 .

6. Calderwood SB, Auclair F, Donohue-Rolfe A, Keusch GT, Mekalanos JJ (1987) Nucleotide sequence of the Shigalike toxin genes of Escherichia coli. Proc Nat Acad Sci USA 84: 4364-4368.

7. CNN Library (2016) E. coli outbreaks - Fast facts.

8. Project Censored (2016) E. coli - Now a national epidemic - Kills 500 Americans annually.

9. Cookson AL, Woodward M (2003) The role of intimin in the adherence of enterohaemorrhagic Escherichia coli (EHEC) $0157 \mathrm{H} 7$ to HEp-2 tissue culture cells and to bovine gut explant tissues. J Med Microbiol 292: 547-553.

10. Griffin PM, Tauxe RV (1991) The epidemiology of infections caused by Escherichia coli O157:H7, other enterohemorrhagic E. coli, and associated hemolytic uremic syndrome. Epid Rev 13: 60-98.

11. Karmali MA (1987) Infection by verotoxin-producing Escherichia coli. Clin Microbiol Rev 2: 15-38.

12. Ohkawa H, Ohishi N, Yagi K (1979) Assay for lipid peroxides in animal tissues by thio-barbituric acid reaction. Anal Biochem 95: 351-358.

13. Zhang W, Bielaszewska M, Kuczius T, Karch H (2002) Identification characterization and distribution of Shiga toxin1 gene variant (stx1c) in Escherichia coli strains isolated from humans. J Clin Microbiol 40: 1441-1446.

14. Beutin L (1999) E. coli as a pathogen in dogs and cats. Vet Res 30: 285-298.

15. Bens M, Vimont S, Ben Mkaddem S, Chassin C, Goujon JM, et al. (2014) Flagellin/TLR5 signalling activates renal collecting duct cells and facilitates invasion and cellular translocation of uropathogenic Escherichia coli. Cell Microbiol $16: 1503-1517$

16. Ohkawa H, Ohishi N, Yagi K (1979) Assay for lipid peroxides in animal tissues by thio-barbituric acid reaction. Anal Biochem 95: 351-358.

17. Paglia DE, Valentine WN (1967) Studies on the quantitative and qualitative characterization of erythrocyte glutathione peroxidase. J Lab Clin Med 70: 158-169. 